\title{
A safety type genetically engineered bacterium with red fluorescence which can be used to degrade organophosphorus pesticides
}

\author{
Q. Li • Y.-J. Wu
}

Received: 16 October 2012/Revised: 13 January 2013/Accepted: 16 March 2013/Published online: 17 April 2013

(C) Islamic Azad University (IAU) 2013

\begin{abstract}
To effectively biodegrade organophosphorus pesticides residue in environment, we constructed a genetically engineered bacterium (GEB) which can not only emit red fluorescence but also degrade organophosphorus pesticides residue, and this GEB can commit suicide when required. Two genes with different functions were placed under the control of different promoters. One was the dual gene expression vector pL-DsRed-pL-OPH in which genes coding for DsRed and organophosphorus hydrolase were independently placed downstream of two pL promoters. These genes could be expressed freely as long as the GEB was alive. The other was the conditional suicide plasmid pDS containing two suicide cassettes designed to induce bacteria to commit suicide when they
\end{abstract}

Q. Li · Y.-J. Wu

Laboratory of Molecular Toxicology, Institute of Zoology,

Chinese Academy of Sciences, Beijing 100080, People's

Republic of China

Q. Li

Chinese Research Academy of Environmental Sciences,

Beijing 100012, People's Republic of China

Y.-J. Wu $(\bowtie)$

Institute of Zoology, Chinese Academy of Sciences, 1-5

Beichenxi Road, Beijing 100101, People's Republic of China

e-mail:wuyj@ioz.ac.cn detect arabinose. The lethal gene used in the suicide plasmid was the nuclease gene of Serratia marcescens without the leader-coding sequence. This was put under the control of the T7 promoter. Applying this type of secure GEB could potentially be a less hazardous environmental strategy in degrading pesticides and contamination.

Keywords Safety type - Genetically engineered microorganism - Autofluorescent protein - Monitoring · Organophosphorus pollutant $\cdot$ Pesticide degradation

\section{Introduction}

Organophosphorus compounds (OPs) are a broad class of neurotoxic chemicals that can be used as pesticides or chemical warfare agents. The wide use of OPs results in severe environmental pollution and growing concern about pesticide residues. The development and application of genetically engineered microorganisms (GEMs) that can degrade OPs would be an efficient way to reduce OPs residues. Organophosphorus hydrolase (OPH) (E.C. 8.1.3.1) is an organophosphotriester hydrolyzing enzyme discovered in the soil microorganisms Pseudomonas diminuta MG and Flavobacterium spp. (Munnecke 1980). $\mathrm{OPH}$ is able to hydrolyze a number of OPs, including substrates containing the P-S bond (Chae et al. 1994; Lai et al. 1995; Kolakowski et al. 1997), and is one of the most common enzymes used in GEMs for breaking down OP pesticide residues.

Although many GEMs, including those with the ability to degrade OP pesticides, have been constructed (UrgunDemirtas et al. 2006; Hong et al. 2010; Khodi et al. 2012), their use is usually limited by the potential risks associated 
with releasing them into the environment, including the movement of genes from such GEMs to other organisms and their potential to adversely affect indigenous microbial populations. To minimize these risks, GEMs intended for release into the environment must be able to be monitored effectively and their distribution limited by means of a biological containment system.

Recently, biotechnology, such as gene probes (Yang and Fox 1996; Matheson et al. 1997), PCR (Amici et al. 1991; Khan et al. 1998), monoclonal antibodies (RamosGonzalez et al. 1992), bioluminescence (Heller et al. 1992; Ripp et al. 2000) and autofluorescent proteins (AFPs) (Gory et al. 2001; Gather and Yun 2011; Ravikumar et al. 2012), has been used to monitor GEMs. Of these, AFPs are the only technology that does not need additional substrates, cofactors, or proteins (Larrainzar et al. 2005). Green fluorescent protein (GFP), discovered in the Pacific Northwest jellyfish, Aequorea victoria in 1962, and DsRed, a red fluorescent protein found in the reef coral Discosoma sp. in 1999 (Matz et al. 1999), are commonly used AFPs. Although many genetically engineered bacteria (GEBs) incorporating GFP have been constructed (Cha et al. 2000; Wu et al. 2001; Sevastsyanovich et al. 2009), relatively few have been engineered to express DsRed. DsRed is superior to GFP in that it is more resistant to photobleaching, has negligible $\mathrm{pH}$ dependence for absorbance or fluorescence across a $\mathrm{pH}$ range of 5-12, and has a significantly red-shifted fluorescence spectrum which minimizes problems associated with light scattering and autofluorescence of the cells (Verkhusha and Lukyanov 2004; Vrzheshch et al. 2000). This paper describes the construction of a GEB capable of red fluorescence, degrading OPs and with an active biological containment (ABC) system by the co-transformation of two plasmids containing different functional genes and promoters. One was a plasmid carrying the gene of DsRed and OPH, which was placed downstream of two lambda $\mathrm{P}_{\mathrm{L}}$ promoters separately. The other was the compatible conditional suicide plasmid pDS containing two copies of the lethal nuclease gene of Serratia marcescens without the leader-coding sequence ( $\mathrm{Li}$ and $\mathrm{Wu}$ 2009).

\section{Materials and methods}

Plasmid construction

The DsRed gene, to which two additional stop codons had been added, was amplified by PCR from pDsRed-N1 (Clontech) and cloned in the EcoRI and BamHI restriction sites of the plasmid pBV220 (obtained from Ms. Liu, Medicine College of Tianjin) (primers used were no. 1 and no. 2, see Table 1). The resultant plasmid was called $\mathrm{pBV}$ DsRed.

The opd gene, which encodes the protein $\mathrm{OPH}$, was amplified from pGEM-T Easy-opd obtained from Dr. Qiao (Institute of Zoology, Chinese Academy of Sciences) (primers used were no. 3 and no. 4, see Table 1). The PCRamplified opd gene was then inserted between the BamHI site and PstI site of pBV220 to obtain the plasmid pBV$\mathrm{OPH}$. Primers were designed to amplify the entire sequences of pBV-DsRed and pBV-OPH, except the cIts857 gene which encodes the repressor protein for transcriptional control in plasmid pBV220 (primers used were no. 5 and no. 6 , see Table 1). The amplified fragment was then self-circularized to construct the plasmids $\mathrm{pL}$ DsRed and pL-OPH. The entire sequence of pL-DsRed was then amplified again and ligated with the fragment amplified from pL-OPH (primers used were no. 5 and no. 7, see Table 1) containing the sequences of the promoters, opd gene and the rrnBT1T2 terminator. The resultant plasmid was designated pL-DsRed-pL-OPH (Fig. 1).

\section{Construction of the GEB}

The plasmids pL-DsRed-pL-OPH and pDS were sequentially transformed into $E$. coli strain BL21-AI ${ }^{\mathrm{TM}}$ $\left(F^{-}{ }_{\text {ompT }} h s d S_{B}\left(r_{B}^{-} m_{B}^{-}\right)\right.$gal dcm araB::T7RNAP-tetA, Invitrogen) using the calcium chloride procedure (Sambrook and Russell 2001) generating a GEB (named as BL21AI-ROS) that can emit red fluorescence, degrade OPs and commit suicide when induced to do so. pDS was a conditional suicide plasmid containing two suicide cassettes designed to induce bacteria to commit suicide when they detect arabinose. The lethal gene used in the suicide plasmid was the nuclease gene of $S$. marcescens without the leader-coding sequence. This was put under the control of the $\mathrm{T} 7$ promoter ( $\mathrm{Li}$ and $\mathrm{Wu} 2009$ ). BL21AI-ROS's red fluorescence and ability to degrade OPs do not require induction, but the cell suicide containment system must be activated by adding arabinose to the culture medium.

Detection of the intensity of fluorescence and GEB growth curve

After being incubated overnight, cultures were transferred into $(2 \%)$ liquid Luria-Bertani (LB) medium to which the appropriate antibiotics, ampicillin $\left(50 \mu \mathrm{g} \mathrm{ml}^{-1}\right)$ and kanamycin $\left(50 \mu \mathrm{g} \mathrm{ml}^{-1}\right)$, had been added and incubated at $30{ }^{\circ} \mathrm{C}$ in a shaker. When optical density $\left(\mathrm{OD}_{600}\right)$ reached the mid-growth phase $(0.5-0.8)$, cultures were separated into two halves. One half was induced by adding $0.01 \%$ arabinose (final concentration, wt/vol), whereas nothing was added to the other which served as a control. Both 
Table 1 Primers used in this study

\begin{tabular}{lll}
\hline No. & Restriction enzymes ${ }^{\mathrm{a}}$ & ${\text { Sequence }\left(5^{\prime} \rightarrow 3^{\prime}\right)^{\mathrm{b}}}$ \\
\hline 1 & EcoRI & GGAATTCATGGTGCGCTCCTCCAAGA \\
2 & Bam $\mathrm{HI}$ & CGGGATCCCTCATTACTACAGGAACAGGTGGTGGC \\
3 & Bam $\mathrm{HI}$ & CGGGATCCATGCAAACGAGAAGGGTTGTGCTCAAGT \\
4 & $P s t \mathrm{I}$ & AACTGCAGTCATGACGCCCGCAAGGTCGGTG \\
5 & Sac I & TTCGAGCTCCGTGCGTGTTGACTATTTTACCT \\
6 & $X b a \mathrm{I}$ & GCTCTAGATCGGCAAGGTGTTCTGGTC \\
7 & NheI & CTTGCTAGCCATGAGCGGATACATATTTGAATG \\
\hline
\end{tabular}

${ }^{a}$ Restriction enzymes that can digest the underlined sequences

${ }^{\mathrm{b}}$ Underlined sequences are restriction sites

halves of each culture continued to be incubated at $30{ }^{\circ} \mathrm{C}$. Samples were collected every $2 \mathrm{~h}$ for $14 \mathrm{~h}$ after which samples were incubated at $30{ }^{\circ} \mathrm{C}$ without shaking and sampled daily for another 9 days. The $\mathrm{OD}_{600}$ and fluorescence of all samples were measured using a Beckman DU800 spectrophotometer and Hitachi F-4500 fluorescence spectrophotometer (excitation wavelength of $558 \mathrm{~nm}$ and emission wavelength of $583 \mathrm{~nm}$, the bandwidth for each was set at $5 \mathrm{~nm}$ ), respectively.

The samples collected during the first $14 \mathrm{~h}$ were used in a plate experiment as follows: Samples were diluted with non-selective $\mathrm{LB}$ medium till their $\mathrm{OD}_{600}$ reached 0.2 , then diluted 1:200 with the same medium. $150 \mu \mathrm{l}$ of the final dilution was spread on different selective plates (LB plate containing $50 \mu \mathrm{g}$ ampicillin $\mathrm{ml}^{-1}, 50 \mu \mathrm{g}$ kanamycin $\mathrm{ml}^{-1}$, or a combination of $50 \mu \mathrm{g}$ ampicillin $\mathrm{ml}^{-1}$ and $50 \mu \mathrm{g}$ kanamycin $\mathrm{ml}^{-1}$. Colonies on the plates were counted after incubation at $30{ }^{\circ} \mathrm{C}$ for $16-24 \mathrm{~h}$ and fluorescence detected using a Leitz DMIRB microscope (Leica, Germany) and by eye under daylight, daily for 5 days.

Preparation of total cell protein

Cells were harvested by centrifugation at $10,000 \times g$ for

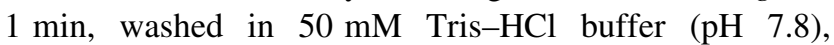
resuspended completely in the same buffer $(200 \mu \mathrm{l}$ vs. starting volume of $1 \mathrm{ml}$ culture) then sonicated on ice for about $2 \mathrm{~min}$ in an ultrasonic processor (Sonics \& Materials, USA) at the following settings: 2-3 (power level), $40 \mathrm{~Hz}$ (amplitude). The resultant mixture was the total cell protein which was used as the source of the protein to be assayed. Protein concentration was determined using the Bradford method with bovine serum albumin (BSA) as the standard (Bradford 1976).
Assay of OPH activity

Ten micrograms $(10 \mu \mathrm{g})$ of total cell protein was resuspended in $1 \mathrm{ml}$ of $50 \mathrm{mM}$ Tris-HCl buffer ( $\mathrm{pH} 7.8$ ) containing $3 \mu \mathrm{l}$ of $50 \mathrm{mM}$ parathion (99\% purity, dissolved in ethanol). The rate of hydrolysis was determined by measuring the formation of $p$-nitrophenol at the optical density of $400 \mathrm{~nm}\left(\mathrm{OD}_{400}\right)$. After the reaction had proceeded at $30{ }^{\circ} \mathrm{C}$ for $1.5 \mathrm{~h}$, the change in absorbance $(400 \mathrm{~nm})$ was measured with a Beckman DU-800 spectrophotometer.

\section{Results and discussion}

In this study, a dual gene expression vector allowing the simultaneous expression of DsRed and OPH was constructed and used in the GEB BL21AI-ROS. Usually, the expression of target proteins in GEMs requires an inducer (Menzella and Gramajo 2004; Vaiphei et al. 2010; Kim et al. 2012), which places an additional cost on the expression of the target protein, thereby reducing the GEMs cost-effectiveness. However, by cloning the target gene downstream of the lambda $\mathrm{P}_{\mathrm{L}}$ promoter, deleting the copy of the lambda cIts857 repressor from the plasmid pBV220 and choosing an appropriate host, we constructed a constitutive protein expression unit. It was fortunate that the host's metabolism was not too severely burdened by the addition of these two free expression units. This expression mode of the dual gene expression vector enlarges the application prospects of plasmid using as a vector for construction of bio-engineered bacteria.

To reduce the potential risk of unintentional and deliberate releases of GEMs, the conditional suicide plasmid pDS was co-transformed with the plasmid pL-DsRed-pL- 
(A)

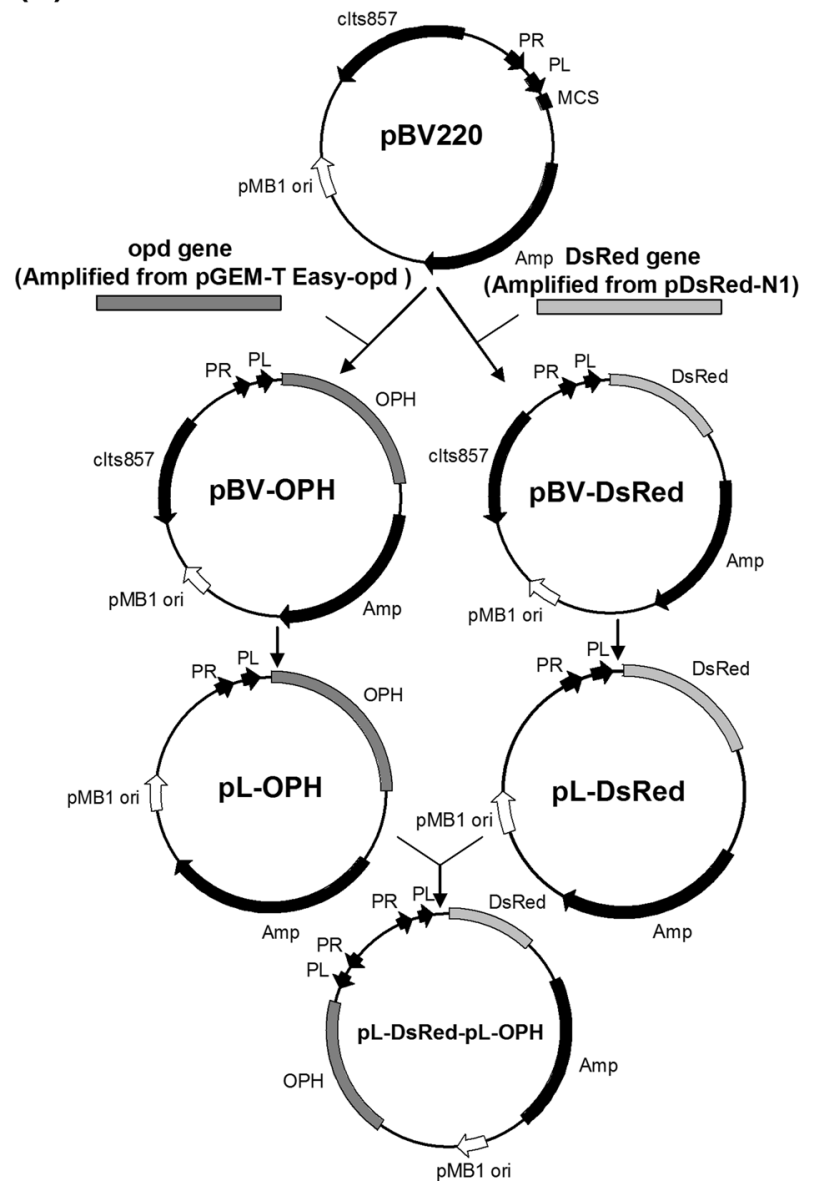

(B)

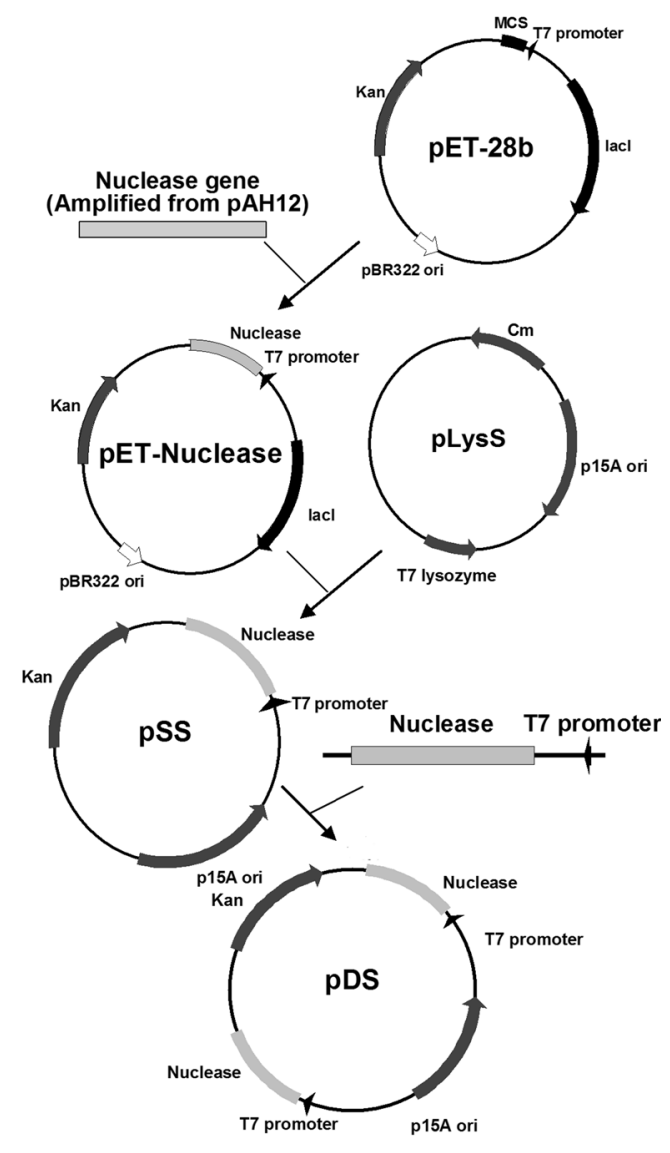

Fig. 1 Construction map of the recombinant plasmid. Cloning and construction of the recombinant plasmid pL-DsRed-pL-OPH (A) and pDS (B)

$\mathrm{OPH}$ in the same cell because it has a different replicon. To improve the efficiency of this suicide plasmid, the suicide cassette was duplicated within it.

Figure 2a shows the growth curves and fluorescence intensity of the GEBs BL21AI-ROS, BL21AI-DS, BL21AI-RO, BL21AI-R, BL21AI-O or BL21AI, which, respectively, correspond to E. coli $\mathrm{BL} 21 \mathrm{AI}^{\mathrm{TM}}$ harboring pL-DsRed-pL-OPH and pDS together, pDS, pL-DsRedpL-OPH, pL-DsRed, pL-OPH, or no plasmid. Growth curves indicated that BL21AI-ROS cells multiplied slightly slower than cells harboring one plasmid or no plasmid during the exponential growth phase. This indicates the host's growth rate reduced by the metabolic burden when the plasmids pL-DsRed-pL-OPH and pDS were co-transformed into the host; however, this handicap was not lethal and did not compromise the function of BL21AI-ROS. After the addition of arabinose, the growth rate of BL21AIROS became much slower than the control eventually stopping completely. To verify the effectiveness of the suicide mechanism, the samples collected during the first $14 \mathrm{~h}$ were spread on different selective plates. Plates of uninduced BL21AI-ROS cells were densely covered by $>20,000$ colonies. No colonies of induced BL21AI-ROS cells were found on plates containing kanamycin, or both kanamycin and ampicillin, but $155 \pm 38$ colonies were found on plates containing ampicillin. The results of the plate experiment showed that the dual suicide system was very effective; however, it became apparent that plasmidloss was a problem. After induction with arabinose, some colonies survived on plates containing ampicillin (about $0.5 \%$ ) but none survived on plates containing kanamycin. Kanamycin resistance is a property of the suicide plasmid pDS, so the absence of BL21AI-ROS from plates containing kanamycin indicates that some BL21AI-ROS lost this plasmid during incubation. To avoid the loss of the suicide plasmid, it may be better to place the dual suicide systems of the truncated nuclease gene on the chromosome, or adopt a new plasmid stability system. The way of 
Fig. 2 Growth curve (a, c) and fluorescence intensity $(\mathbf{b}, \mathbf{d})$ of the GEBs. The cultures were separated into two halves. One half was induced by adding $0.01 \%$ arabinose, whereas nothing was added to the other which served as a control. Both halves of each culture continued to be incubated at $30{ }^{\circ} \mathrm{C}$. Samples were collected every $2 \mathrm{~h}$ for $14 \mathrm{~h}$ after which samples were incubated at $30{ }^{\circ} \mathrm{C}$ without shaking and sampled daily for another 9 days. The $\mathrm{OD}_{600}(\mathbf{a}$, c) and fluorescence $(\mathbf{b}, \mathbf{d})$ of all samples were measured, respectively
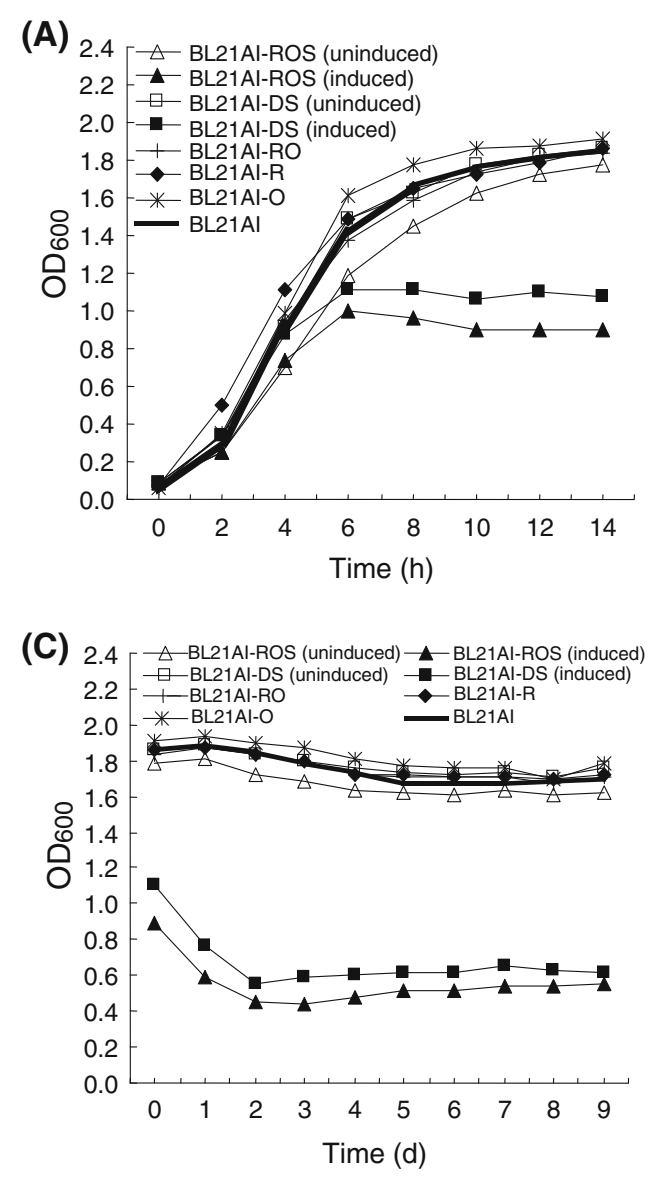

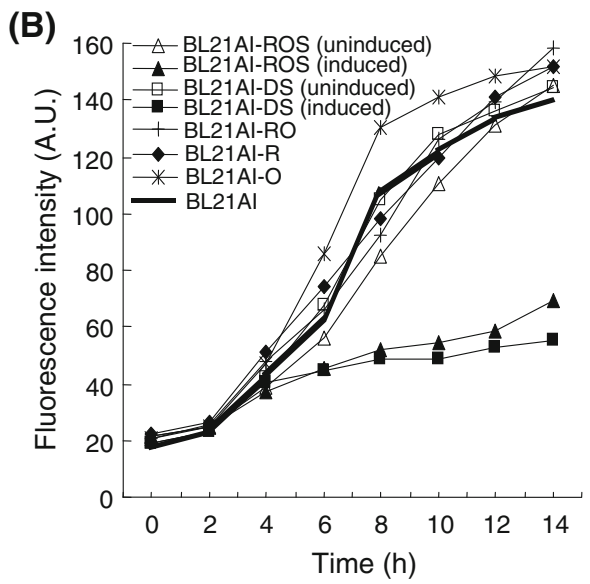

(B)

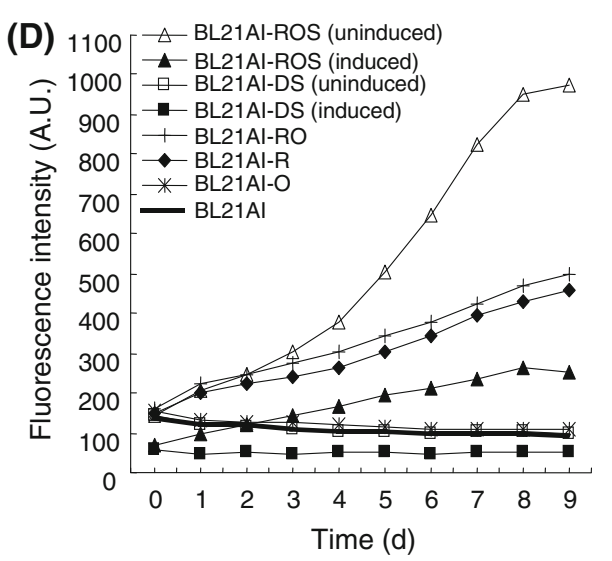

cell-cell communication built to regulate the density of an E. coli population by coupling gene expression to cell survival and death (You et al. 2004), and antibiotic-free plasmid selection and maintenance (Cranenburgh et al. 2001, 2004) may be good ideas to overcome these deficiencies.

During the first $14 \mathrm{~h}$ samples showed little variation in fluorescence intensity (range 40-150) (Fig. 2b), this variation could be attributed to changes in optical density. After $14 \mathrm{~h}$, all samples were stored without shaking at $30{ }^{\circ} \mathrm{C}$ for 9 days to allow the red fluorescence proteins to mature and their optical density $\left(\mathrm{OD}_{600}\right)$ and their fluorescence was measured daily. During this 9-day period, the optical density of the samples changed little, except for that of the induced samples which declined markedly (Fig. 2c). At the same time, the samples' fluorescence changed dramatically (Fig. 2d). The fluorescence of all samples harboring plasmids with the DsRed gene all increased over the 9-day period. The fluorescence of BL21AI-ROS was the strongest (over 1,000), almost twice that of BL21AI-R and BL21AI-RO after 9 days. The fluorescence of BL21 $\mathrm{AI}^{\mathrm{TM}}$, which lacked the DsRed gene, showed no increase during the 9-day period. When a fluorescent microscope was used to detect bacterial colonies; strong red fluorescence was detected from colonies of BL21AI-ROS, BL21AI-R and BL21AI-RO after about 2 days (Fig. 3a). After 5 days, obvious red fluorescence could be detected in these colonies with the naked eye in daylight (Fig. 3c). No red fluorescence was detected in the control BL21 $\mathrm{AI}^{\mathrm{TM}}$ colony, either with a fluorescent microscope or with the naked eye (Fig. 3b, d).

It took about 2 days before the red fluorescence emitted by BL21AI-ROS, BL21AI-R and BL21AI-RO could be detected with a fluorescent microscope, and about 5 days before this could be seen directly with the naked eye in daylight. Although this is a relatively long time, this shortcoming is outweighed by the relative ease of detecting the GEB once it begins fluorescing. For example, individual colonies of BL21AI-ROS can be identified on agar plates without a special light source, a feature that greatly simplifies the screening of bacterial colonies. 

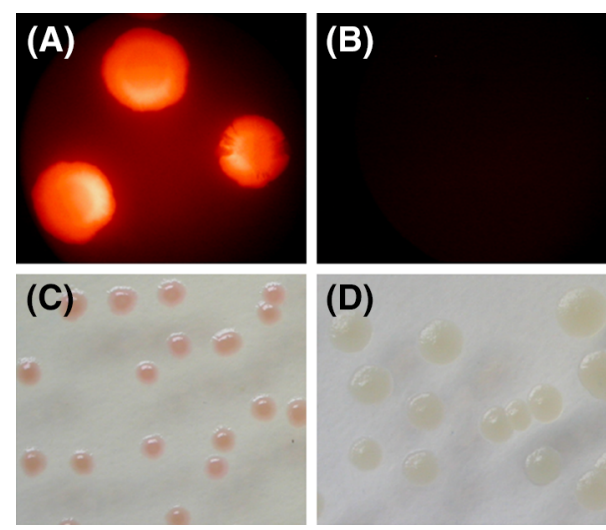

(D)

Fig. 3 Images of the GEBs. Images of colonies of BL21AI-ROS (a) and BL21AI (b) on LB agar plates photographed through a fluorescent microscope (magnification: $10 \times 4$ ). Images of colonies of BL21AI-ROS (c) and BL21AI (d) on LB agar plate photographed directly in daylight (all photos were taken with a Nikon 4500 digital camera)

The growth of BL21AI-ROS colonies following the addition of arabinose was slower than that of the uninduced control colonies, a trend reflected in their fluorescence intensity curves. To some extent, this result confirms previous studies which showed that fluorescence can be used to monitor GEMs (Leff and Leff 1996; Bastos et al. 2001).

OPH activity of the GEBs was determined by calculating parathion cleavage rate. Parathion can be hydrolyzed to $p$-nitrophenol by $\mathrm{OPH}$, the products of this reaction, $p$ nitrophenol, displays a strong absorption band at $400 \mathrm{~nm}$ at $\mathrm{pH}$ 7.8. This absorbance at $400 \mathrm{~nm}\left(\mathrm{OD}_{400}\right)$ is proportional to the number of moles of $p$-nitrophenol produced and parathion hydrolyzed. As shown in Fig. 4, the total cell protein of BL21AI-ROS, BL21AI-RO and BL21AI-O, all had catalytic activity and that this activity increased with placing of those cells at $30^{\circ} \mathrm{C}$, at least within the first 8 days. Among these bacteria, BL21AI-ROS had the best degradation ability; BL21AI-RO was the second best. During the whole detection process, the $\mathrm{OD}_{400}$ value of the controls (E. coli $\mathrm{BL} 21 \mathrm{AI}^{\mathrm{TM}}$ without plasmid) changed little.

The fluorescence and OPH activity of BL21AI-ROS were stronger than that of cells carrying the pL-DsRed-pL$\mathrm{OPH}, \mathrm{pL}-\mathrm{DsRed}$ or pL-OPH plasmids alone. This may be attributed to possible differences in the gene copy numbers. These results suggest that BL21AI-ROS functioned at least as efficiently, or better, than cells harboring the pL-DsRedpL-OPH plasmid alone.

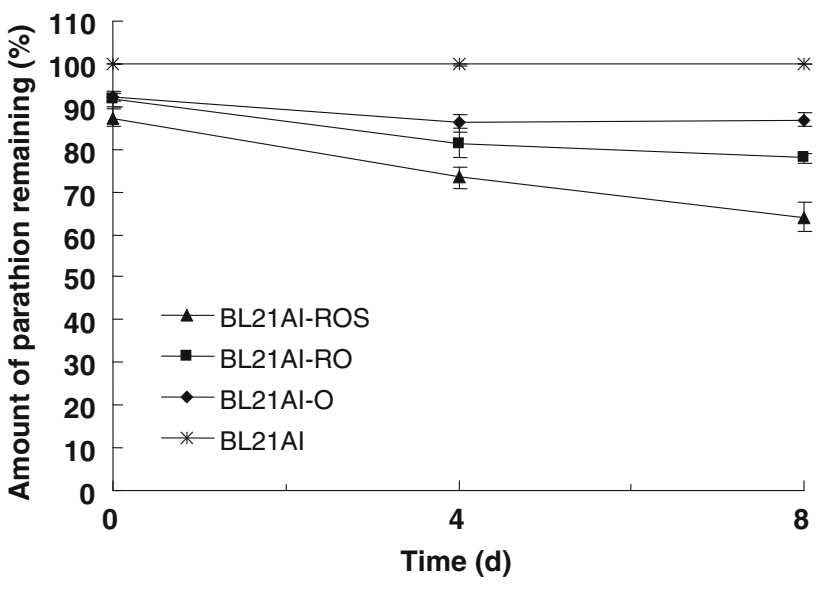

Fig. $4 \mathrm{OPH}$ activity of the GEBs. OPH activity of total cell protein (TCP) of samples of BL21AI-ROS, BL21AI-RO, BL21AI-O, and BL21AI incubated for $14 \mathrm{~h}$ (the zero day), the 4th day and the 8th day. The degradation of parathion by $\mathrm{OPH}$ from the genetically engineered bacteria was expressed as the remaining amount of parathion (\%), which is converted and calculated by the standard curve of $p$-nitrophenol (the value of $\mathrm{OD}_{400}$ is proportional to moles of $p$-nitrophenol produced)

Compared with our previous study, the BL21AI-ROS in this study has particular fluorescence characteristic. DsRed and $\mathrm{OPH}$ were expressed independently in BL21AI-ROS using a dual gene expression vector, rather than fusion protein expression. Compared with GFP, DsRed has excellent resistance to $\mathrm{pH}$ extremes and photobleaching, and these features make it more conducive to the tracking and monitoring of GEMs in the field. The features of BL21AI-ROS including the characteristics of OPH, red fluorescence, and the $\mathrm{ABC}$ system increase its safety in the application of field bioremediation although this study also showed the similar deficiencies in the previous study, which were field induction of the suicide function and antibiotic resistance marker genes, besides loss of the suicide plasmid.

\section{Conclusion}

In summary, our results demonstrate that it is possible to construct a plasmid containing two free expression units controlled by two independent $\mathrm{P}_{\mathrm{L}}$ promoters and add a containment system to a GEB designed to expresses a specific protein and emit red fluorescence. This type of secure GEB can not only degrade OP residue but also commit suicide when required after application, which 
could potentially be a less hazardous environmental strategy in degrading pesticides and contamination.

Acknowledgments We thank Prof. W. Wackernagel for E. coli TGE900 with the plasmid pAH12, Prof. C. L. Qiao for providing the plasmid pGEM-T-opd, Ms. R. Liu for the plasmid pBV220. This research was supported by the CAS Innovation Program (KZCX2EW-404) and SKLECE program (KF2010-16).

\section{References}

Amici A, Bazzicalupo M, Gallori E, Rollo F (1991) Monitoring a genetically engineered bacterium in a freshwater environment by rapid enzymatic amplification of a synthetic DNA "numberplate". Appl Microbiol Biotechnol 36:222-227

Bastos AER, Cassidy MB, Trevors JT, Lee H, Rossi A (2001) Introduction of green fluorescent protein gene into phenoldegrading Alcaligenes faecalis cells and their monitoring in phenolcontaminated soil. Appl Microbiol Biotechnol 56:255-260

Bradford MM (1976) A rapid and sensitive method for the quantitation of microgram quantities of protein utilizing the principle of protein-dye binding. Anal Biochem 72:248-254

Cha HJ, Wu CF, Valdes JJ, Rao G, Bentley WE (2000) Observations of green fluorescent protein as a fusion partner in genetically engineered Escherichia coli: monitoring protein expression and solubility. Biotechnol Bioeng 67:565-574

Chae MY, Postula JF, Raushel FM (1994) Stereospecific enzymatic hydrolysis of phosphorus-sulfur bonds in chiral organophosphate triesters. Bioorg Med Chem Lett 4:1473-1478

Cranenburgh RM, Hanak JA, Williams SG, Sherratt DJ (2001) Escherichia coli strains that allow antibiotic-free plasmid selection and maintenance by repressor titration. Nucleic Acids Res 29:E26. doi:10.1093/nar/29.5.e26

Cranenburgh RM, Lewis KS, Hanak JA (2004) Effect of plasmid copy number and lac operator sequence on antibiotic-free plasmid selection by operator-repressor titration in Escherichia coli. J Mol Microbiol Biotechnol 7:197-203

Gather MC, Yun SH (2011) Lasing from Escherichia coli bacteria genetically programmed to express green fluorescent protein. Opt Lett 36:3299-3301

Gory L, Montel MC, Zagorec M (2001) Use of green fluorescent protein to monitor Lactobacillus sakei in fermented meat products. FEMS Microbiol Lett 194:127-133

Heller S, Buhler S, Kilz S, Mieschendahl M (1992) Bioluminescencebased detection of genetically engineered microorganisms in nonsterile river water. Microb. Releases 1:35-39

Hong Y, Zhou J, Hong Q, Wang Q, Jiang J, Li S (2010) Characterization of a fenpropathrin-degrading strain and construction of a genetically engineered microorganism for simultaneous degradation of methyl parathion and fenpropathrin. J Environ Manage 91:2295-2300

Khan AA, Jones RA, Cerniglia CE (1998) Rapid method for the detection of genetically engineered microorganisms by polymerase chain reaction from soil and sediments. J Ind Microbiol Biotechnol 20:90-94

Khodi S, Latifi AM, Saadati M, Mirzaei M, Aghamollaei H (2012) Surface display of organophosphorus hydrolase on E. coli using $\mathrm{N}$-terminal domain of ice nucleation protein InaV. J Microbiol Biotechnol 22:234-238

Kim HJ, Kwon YD, Lee SY, Kim P (2012) An engineered Escherichia coli having a high intracellular level of ATP and enhanced recombinant protein production. Appl Microbiol Biotechnol 94:1079-1086

Kolakowski JE, DeFrank JJ, Harvey SP, Szafraniec LL, Beaudry WT, Lai K, Wild JR (1997) Enzymatic hydrolysis of the chemical warfare agent VX and its neurotoxic analogues by organophosphorus hydrolase. Biocatal Biotransform 15:297-312

Lai K, Stolowich NJ, Wild JR (1995) Characterization of P-S bond hydrolysis in organophosphorothioate pesticides by organophosphorus hydrolase. Arch Biochem Biophys 318:59-64

Larrainzar E, O'Gara F, Morrissey JP (2005) Applications of autofluorescent proteins for in situ studies in microbial ecology. Annu Rev Microbiol 59:257-277

Leff LG, Leff AA (1996) Use of green fluorescent protein to monitor survival of genetically engineered bacteria in aquatic environments. Appl Environ Microbiol 62:3486-3488

Li Q, Wu YJ (2009) A fluorescent genetically engineered microorganism that degrades organophosphates and commits suicide when required. Appl Microbiol Biotechnol 82:749-756

Matheson VG, Munakata-Marr J, Hopkins GD, McCarty PL, Tiedje JM, Forney LJ (1997) A novel means to develop strain-specific DNA probes for detecting bacteria in the environment. Appl Environ Microbiol 63:2863-2869

Matz MV, Fradkov AF, Labas YA, Savitsky AP, Zaraisky AG, Markelov ML, Lukyanov SA (1999) Fluorescent proteins from nonbioluminescent anthozoa species. Nat Biotechnol 17:969-973

Menzella HG, Gramajo HC (2004) Recombinant protein production in high cell density cultures of Escherichia coli with galactose as a gratuitous inducer. Biotechnol Prog 20:1263-1266

Munnecke DM (1980) Enzymatic detoxification of waste organophosphate pesticides. J Agric Food Chem 28:105-111

Ramos-Gonzalez MI, Ruiz-Cabello F, Brettar I, Garrido F, Ramos JL (1992) Tracking genetically engineered bacteria: monoclonal antibodies against surface determinants of the soil bacterium Pseudomonas putida 2440. J Bacteriol 174:2978-2985

Ravikumar S, Ganesh I, Yoo I, Hong SH (2012) Construction of a bacterial biosensor for zinc and copper and its application to the development of multifunctional heavy metal adsorption bacteria. Process Biochem 47:758-765

Ripp S, Nivens DE, Werner C, Sayler GS (2000) Bioluminescent most-probable-number monitoring of a genetically engineered bacterium during a long-term contained field release. Appl Microbiol Biotechnol 53:736-741

Sambrook J, Russell DW (2001) Molecular cloning: a laboratory manual, 3rd edn. Cold Spring Harbor Laboratory Press, New York

Sevastsyanovich Y, Alfasi S, Overton T, Hall R, Jones J, Hewitt C, Cole J (2009) Exploitation of GFP fusion proteins and stress avoidance as a generic strategy for the production of high-quality recombinant proteins. FEMS Microbiol Lett 299:86-94

Urgun-Demirtas M, Stark B, Pagilla K (2006) Use of genetically engineered microorganisms (GEMs) for the bioremediation of contaminants. Crit Rev Biotechnol 26:145-164

Vaiphei ST, Mao L, Shimazu T, Park JH, Inouye M (2010) Use of amino acids as inducers for high-level protein expression in the single-protein production system. Appl Environ Microbiol 76:6063-6068

Verkhusha VV, Lukyanov KA (2004) The molecular properties and applications of anthozoa fluorescent proteins and chromoproteins. Nat Biotechnol 22:289-296

Vrzheshch PV, Akovbian NA, Varfolomeyev SD, Verkhusha VV (2000) Denaturation and partial renaturation of a tightly tetramerized DsRed protein under mildly acidic conditions. FEBS Lett 487:203-208 
Wu CF, Valdes JJ, Rao G, Bentley WE (2001) Enhancement of organophosphorus hydrolase yield in Escherichia coli using multiple gene fusions. Biotechnol Bioeng 75:100-103

Yang Y, Fox GE (1996) An Archaea 5S rRNA analog is stably expressed in Escherichia coli. Gene 168:81-85
You L, Cox RS, Weiss R, Arnold FH (2004) Programmed population control by cell-cell communication and regulated killing. Nature 428:868-871 